\title{
Temperate glacier time response from field data
}

\author{
D. M. McClung \\ Departments of Civil Engineering and Geography, University of British Columbia, Vancouver, British Columbia V6T 124, Canada \\ RICHARD L. ARMSTRONG \\ Cooperative Institute for Research in Environmental Sciences, University of Colorado, Boulder, Colorado 80309, U.S.A.
}

\begin{abstract}
The relationship of glacier response due to mass-balance changes is of fundamental importance when climate variations are to be understood. In this paper, two aspects of the problem are analyzed from field data: (1) advance/retreat of the glacier terminus due to changes in mass balance, and (2) cross-correlation of mass-balance data from two glaciers in the same climate zone. The results show: (1) the terminus can respond quickly in accordance with expected minimum time-scale, and (2) two glaciers in the same general climate zone may have very different yearly mass balance and advance/retreat behaviour. This latter result indicates the importance of local climate variations.
\end{abstract}

\section{INTRODUCTION}

Field observations and measurements indicate that temperate alpine glaciers are sensitive indicators of climate. In particular, advance and retreat are governed by changes in mass balance. On a global scale, it is likely along with variability of Arctic sea ice, that glaciological evidence for global climate change will appear first with respect to advance and retreat of temperate glaciers. Jóhannesson and others (1989a, b) presented a simple theory for time response of advance/retreat due to massbalance changes based only on volume change caused by mass-balance perturbations. In this paper, the theory of Jóhannesson and others is applied by a time-series analysis of field measurements. In particular, field measurements of mass balance and terminus position of Blue Glacier reported by Armstrong (1989) and Spicer (1989) are used. The results show agreement with the theory within an order of magnitude.

An additional aspect of the problem is explored by a time-series analysis of mass-balance data for Blue Glacier and South Cascade Glacier (Krimmel, 1989). Boțh of these glaciers are in the same general maritime climate zone but separated by $200 \mathrm{~km}$. However, their mass balance and advance/retreat history over the past 30 years appear radically different (Armstrong, 1989). Cross-correlation of time-series records of mass balance shows that the mass balances are essentially uncorrelated for a given year but there is a significant correlation with a lag of 3 years. However, it is unlikely that this latter result is of substantial importance.

\section{THEORY}

Jóhannesson and others (1989a, b) derived simple order-ofmagnitude relationships to illustate the time- and space- dependent response of temperate (non-surge type) glaciers to mass-balance changes. Their theory essentially involves relating the total rate of change of glacier mass per unit time $(\mathrm{d} M / \mathrm{d} t)$ to $Q_{\mathrm{b}}$ : the balance flux evaluated at the glacier terminus. At the terminus, $Q_{\mathrm{b}}$ is represented by (Raymond, 1980):

$$
Q_{\mathrm{b}}=\int \rho \dot{b} \mathrm{~d} A \approx \frac{\mathrm{d} M}{\mathrm{~d} t} .
$$

In Equation (1), $b$ is net mass balance, $A$ is horizontal area of the glacier above the terminus and $\rho$ is ice density, and the integral is taken over the entire glacier area above the terminus.

By assuming that small changes in glacier volume (due to mass-balance changes) result primarily in area changes at the terminus by extension/retreat, Jóhannesson and others (1989a) showed that the minimum (order-ofmagnitude) time-scale for response contained in Equation (1) is:

$$
T \approx \frac{H}{\dot{b}_{\mathrm{t}}} .
$$

In Equation (2), $H$ is a thickness scale for the glacier (e.g. average of maximum glacier thickness $(\mathrm{m}))$ and $\dot{b}_{\mathrm{t}}$ is an index of ablation rate at the terminus $\left(\mathrm{m} \mathrm{a}^{-1}\right)$. Readers are referred to Jóhannesson and others (1989a, b) for a more complete discussion of the implications of Equation (2).

\section{ANALYSIS}

The area-averaged net mass balance of Blue Glacier for the period 1956-86 is shown in Figure 1 (Armstrong, 1989). The terminus position recorded relative to a point below the glacier which the terminus reached in 1938 (Spicer, 1989) is shown in Figure 2 for the same period. 


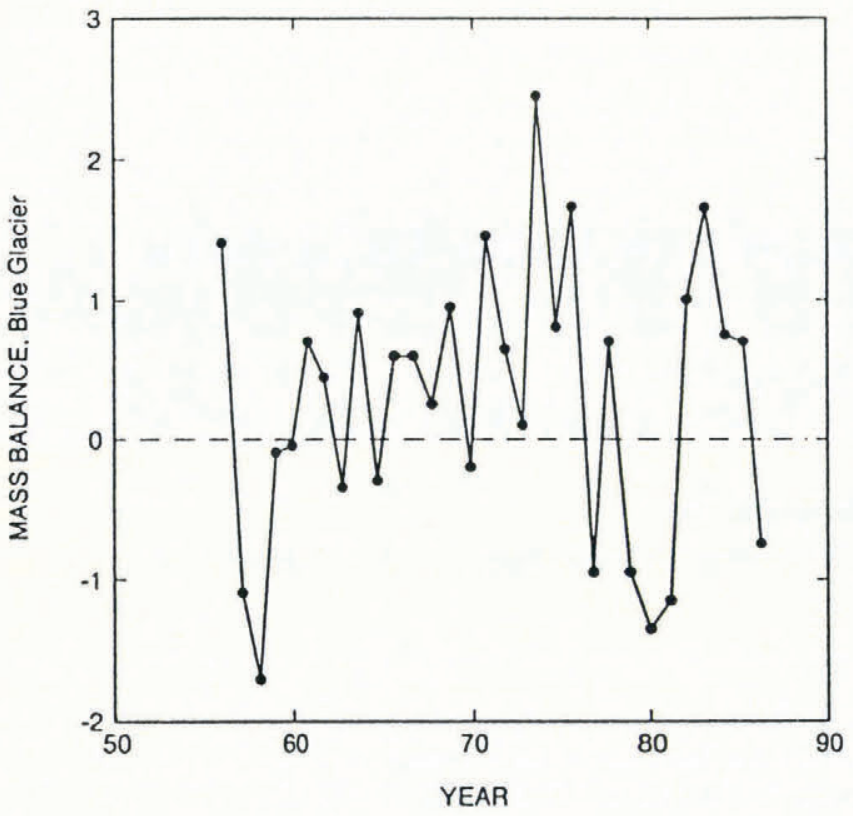

Fig. 1. Area-averaged net mass balance of Blue Glacier ( $m$ water) as a function of time. Data from Armstrong (1989).

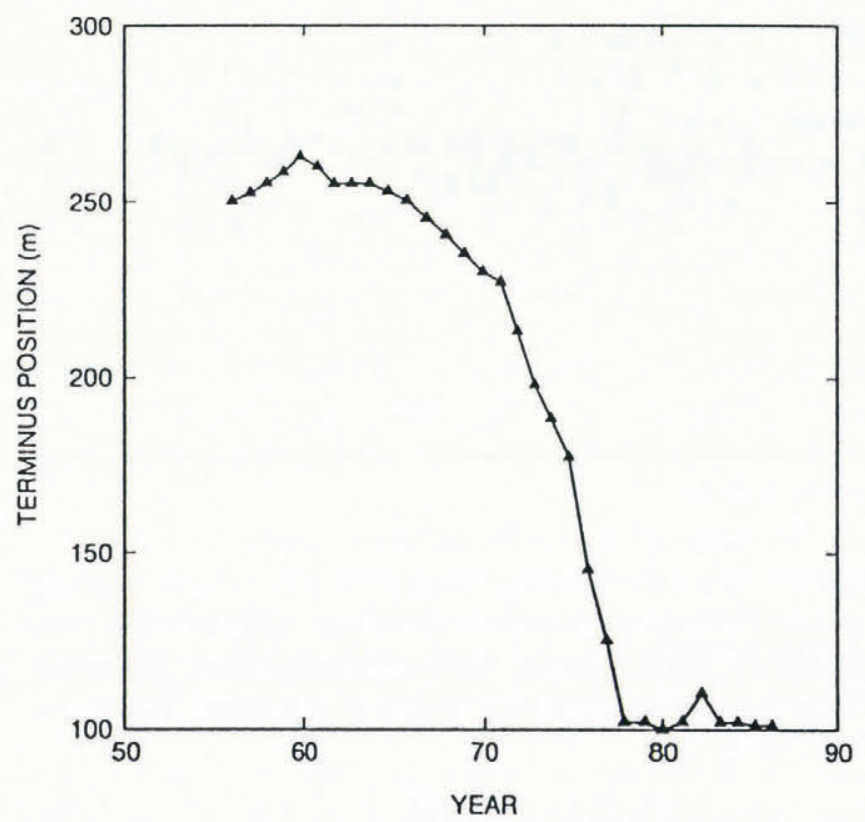

Fig. 2. Terminus position of Blue Glacier in meters from the 1938 position below the glacier. A terminus-position decrease means glacier advance. Data adapted from Spicer (1989).

Note, therefore, that positive increase in terminus position signifies terminus retreat.

A time-series analysis was performed for the data depicted in Figures 1 and 2 by calculation of the crosscorrelation of the series. Analysis of the raw data showed that the highest correlation coefficients occurred for lags of 7-12 years where lag means response time for advance of the terminus corresponding to positive increase in mass balance. These correlation coefficients varied between -0.24 and -0.33 (lag of 10 years). Negative coefficients

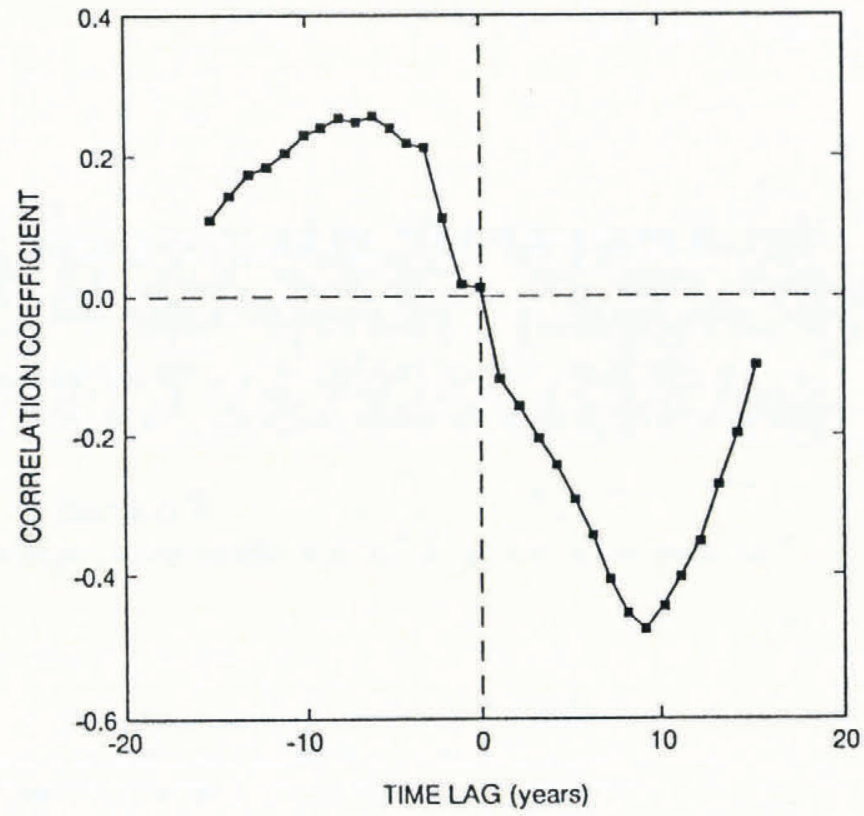

Fig. 3. Cross-correlation of Blue Glacier mass balance with terminus position. Mass-balance data in Figure 1 were smoothed over a time-scale of 6 years before the analysis was performed.

were obtained, since the 1938 reference point is below the present terminus: when the terminus advances, distance from the reference point decreases (See Fig. 2). For the highest correlation -0.33 (at 10 years' lag), the standard error is 0.22 . This lag was the most significant correlation between the two series; it had the highest correlation coefficient and highest ratio of correlation coefficient to standard error (1.5).

Since terminus fluctuations represent a time-integrated response, the mass-balance data were smoothed over a suitable time-scale in order to compare crosscorrelations for two series with similar time-scales of fluctuations. Figure 3 shows cross-correlation of mass balance with terminus position with mass-balance data smoothed (using moving averages) over a time period of 6 years. This smoothing period gave optimum correlation between the two series: other smoothing time periods between 2 and 10 years (and greater) showed lower values and less significance for the correlation coefficients. The analysis in Figure 3 (and that of the raw data) shows that the terminus lags positive mass-balance input by a timescale of about 10 years. For all the values of correlation coefficients plotted in Figure 3, only those with lags between 7 and 11 years equal or exceed two standard errors in the analysis. The positive correlation coefficients for lags of -10 to -5 years are not significant, since they are comparable to the noise (one standard error) in the analysis.

For Blue Glacier, a relevant thickness scale is about 100-200 m (Meier and others, 1974) with ablation rates there of about 3-5 $\mathrm{m} \mathrm{a}^{-1}$ (Armstrong, 1989). From Equation (2), this gives a minimum time-scale of about 20 years which is in rough agreement with the analysis. Mass-balance data from Blue Glacier are not available for much more than about 30 years, so the possibility of longer time-scale interactions cannot be determined. 


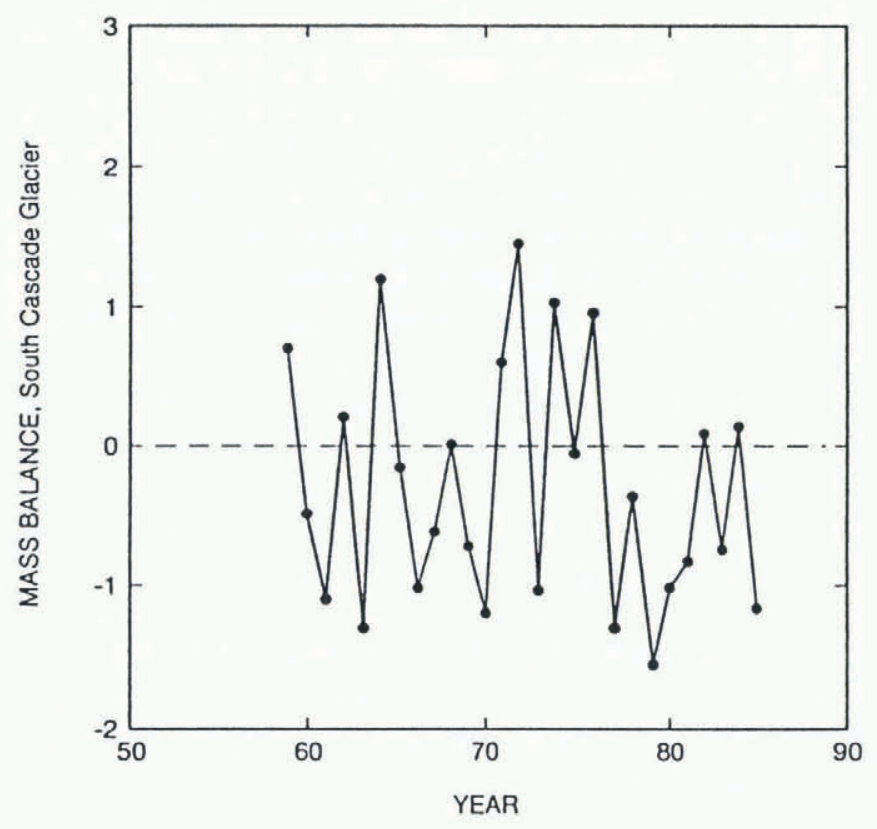

Fig. 4. Area-averaged net mass balance of South Cascade Glacier ( $m$ water) as a function of time. Data from Krimmel (1989).

\section{MASS-BALANCE COMPARISONS}

Mass-balance data (Krimmel, 1989) from South Cascade Glacier are shown in Figure 4. South Cascade Glacier is the only other glacier (besides Blue Glacier) in the northwestern United States (Alaska excluded) with a long-term mass-balance record. During the period 195885 , South Cascade Glacier lost about $10 \mathrm{~m}$ water equivalent averaged over the glacier surface (see Krimmel (1989) for presentation of data and discussion of accuracy) with a terminus-retreat distance near $400 \mathrm{~m}$. During the same period, Blue Glacier had a slightly positive mass balance and advance of about $150 \mathrm{~m}$. Therefore, there are significant differences in the massbalance behaviour of these glaciers even though they are in the same general maritime climate zone and they occupy nearly the same altitude zones. Measurement errors for Blue Glacier are $\pm 10-15 \%$ for ice ablation and $\pm 10-20 \%$ for residual accumulation (Armstrong, 1989).

In Figure 5, mass-balance data from Blue Glacier (Fig. 1) and South Cascade Glacier (Fig. 4) are crosscorrelated as a function of time lag in years. Analysis showed that the cross-correlations are significant only at lags of -3 years (correlation of 0.55 , standard error 0.20 ) and -5 years (correlation 0.40 , standard error 0.20 ). These comparisons add to the differences between the two glaciers; not only are the mass-balance and terminus histories different over the 30 years' comparison, individual (zero-lag) yearly balances do not seem to correlate either.

\section{DISGUSSION}

A time-series analysis of terminus advance and retreat for Blue Glacier indicates that positive mass balances can cause terminus advance in about a 10 year time-scale. This result is in rough agreement with the theory of

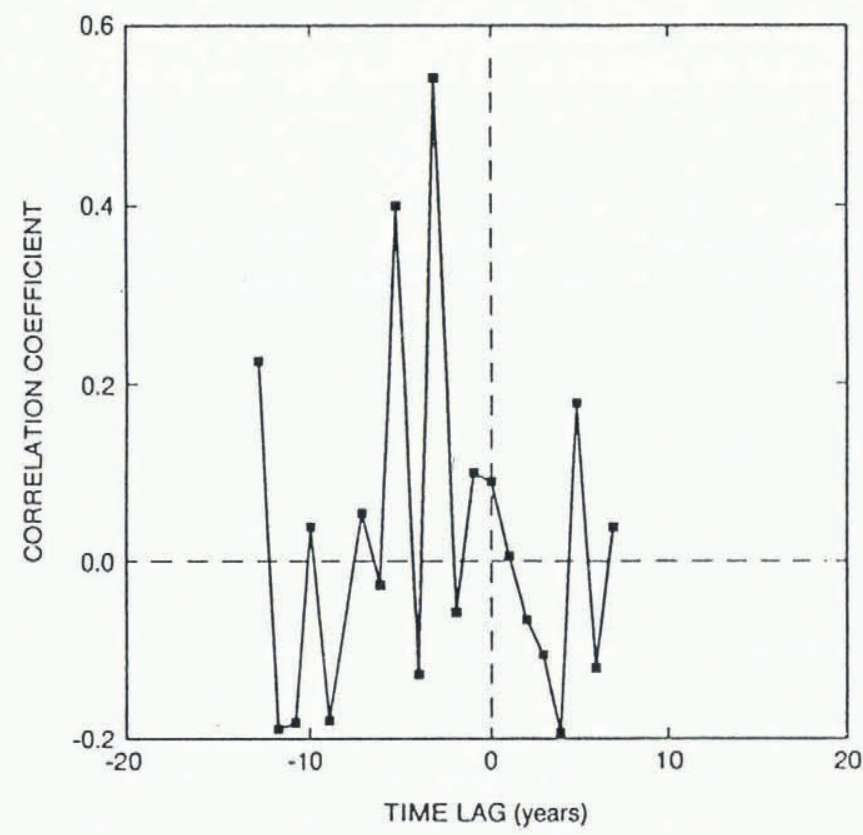

Fig. 5. Cross-correlation of mass-balance data from Blue Glacier and South Cascade Glacier (Figs 1 and 4).

Jóhannesson and others (1989a, b) that a time-scale on the order of 10-20 years is possible for minimum response. This result also agrees with common field observations that advance and retreat of temperate (non-surge) glaciers can be rapid and of the same order as the data and theory indicated. Due to the short length of the time series, it is not possible to comment, from these measurements, on possible response times greater than 30 years.

One possible complication with respect to evaluation of the response time of Blue Glacier is the complexity of the geometry of the glacier terminus (Spicer, 1989). However, the order-of-magnitude theory applied here makes this aspect of the problem beyond the scope of the present paper.

Comparison of mass-balance histories of Blue Glacier and South Cascade Glacier indicates that yearly balances do not correlate. At zero lag, the cross-correlation gave a correlation coefficient of 0.092 (standard error 0.192) which is not close to being significant. This result further enhances the differences between the mass balance and advance/retreat histories of these glaciers. Together, the results may show that a sample size of two is too small to characterize climate implications from glacier fluctuations in a general area; specifics of local climate are important. Since Blue Glacier is significantly closer to the moisture sourc

e (Pacific Ocean) than South Cascade Glacier, the local climate may differ significantly from that of South Cascade Glacier. Even though South Cascade Glacier is in a drier area than Blue Glacier, both glaciers usually intercept the same storms and the general weather patterns are similar. Therefore, one might expect mass balances to cross-correlate on a yearly basis. Apparently, local climate differences dominate over general climate in this case. These results are in contrast to data reported by Schmok and Clarke (1990) from Place and Sentinel Glaciers in the Coast Mountains of southern British 
Columbia. A cross-correlation analysis (24 years of records) of net-balance data from these glaciers gave a correlation coefficient of 0.84 at zero lag with a standard error of 0.204 ; a highly significant result. Place and Sentinel Glaciers are separated by only $65 \mathrm{~km}$ in a northsouth configuration; apparently, in this case the local climate is similar enough to produce good correlation in mass balance.

\section{REFERENCES}

Armstrong, R. L. 1989. Mass balance history of Blue Glacier, Washington, USA. In Oerlemans, J., ed. Glacier fluctuations and climatic change. Dordrecht, Kluwer Academic Publishers, 183-192.

Jóhannesson, T., C. F. Raymond and E. D. Waddington. 1989a. A simple method for determining the response time of glaciers. In Oerlemans, J., ed. Glacier fluctuations and climatic change. Dordrecht, Kluwer Academic Publishers, 343-352.

Jóhannesson, T., C. F. Raymond and E. D. Waddington. 1989b. Time-scale for adjustment of glaciers to changes in mass balance. 7. Glaciol., 35(121), 355-369.

Krimmel, R. M. 1989. Mass balance and volume of South Cascade Glacier, Washington, 1958-1985. In Oerlemans, J., ed. Glacier fluctuations and climatic change. Dordrecht, Kluwer Academic Publishers, 193-206.

Meier, M. F., W. B. Kamb, C. R. Allen and R. P. Sharp. 1974. Flow of Blue Glacier, Olympic Mountains, Washington, U.S.A. F. Glaciol., 13(68), 187-212.

Raymond, C.F. 1980. Temperate valley glaciers. In Colbeck, S. C., ed. Dynamics of snow and ice masses. New York, Academic Press, 79-139.

Schmok, J. and G. K. C Clarke. 1990. Mass-balance, geodetic and photographic surveys of Sentinel, Place and Helm glaciers: 1989 balance year. Ottawa, Environment Canada. National Hydrology Research Institute.

Spicer, R. C. 1989. Recent variations of Blue Glacier, Olympic Mountains, Washington, U.S.A. Arct. Alp. Res., 21(1), 1-21.

The accuracy of references in the text and in this list is the responsibility of the authors, to whom queries should be addressed. 